\title{
Proses Pengepresan Busana Wanita \\ Di Kelurahan Klamalu Distrik Mariat Kabupaten Sorong
}

\author{
Ahmad Jamil ${ }^{1}$, Digor Mufti ${ }^{2}$, Nina Aprilia ${ }^{3}$ \\ ${ }^{1,2,3}$ Fakultas Ekonomi, Universitas Muhammadiyah Sorong, Indonesia \\ *E-mail: jamilscout@gmail.com
}

\begin{abstract}
ABSTRAK
Pelatihan ini bertujuan untuk mengetahui pentingnya pengepresan terhadap hasil busana yang di inginkan serta memberi pengetahuan tentang peralatan yang digunakan dalam pengepresan, teknik-teknik yang harus diperhatikan serta tahap-tahap pengepresan yang baik dan benar. penelitian ini menggunakan metode penelitian deskriptif kualitatif. Hasil dari pelatihan ini yaitu masyarakat menjadi mengerti bagian-bagian tertentu yang masuk dalam proses pengepresan seperti 1. Kampuh, 2.lipit, 3.lapisan dalam(inferancing), 4.komponen-komponen busana. Teknikteknik pengepresan yang perlu diperhatikan, Peralatan yang digunakan untuk menunjang proses pengepresan, serta tahap-tahap pengepresan yang benar. Karena sebaik apapun teknik menjahit yang dilakukan jika teknik pengepresan tidak di lakukan dengan baik maka busana yang dihasilkan tidak sesuai bentuk yang diinginkan.
\end{abstract}

Kata kunci: Pengepresan, Busana wanita, Kelurahan Klamalu

\section{Women's Clothing Pressing Process In Klamalu Village, Mariat District, Sorong Regency}

\begin{abstract}
This training aims to determine the importance of pressing the desired clothing results and to provide knowledge about the equipment used in pressing, the techniques that must be considered and the stages of pressing properly and correctly. This research uses descriptive qualitative research methods. The result of this training is that the community understands certain parts that are included in the pressing process, such as 1. Kampuh, 2.lipit, 3. inner layers (inferancing), 4. clothing components. Pressing techniques that need to be considered, the equipment used to support the pressing process, as well as the correct pressing stages. Because no matter how good the sewing technique is, if the pressing technique is not done properly, the resulting clothing does not match the desired shape.
\end{abstract}

Keywords: Pressing, Women's clothing, Klamalu village

\section{PENDAHULUAN}

Manusia merupakan makhluk hidup yang lebih sempurna dibandingkan dengan makhluk hidup lainnya, dalam kehidupannya manusia selalu berinteraksi dengan manusia lain sehingga manusia disebut juga dengan makhluk sosial. Kehidupan manusia sebagai makhluk sosial selalu membutuhkan aspek lain untuk membantu dalam keberlangsungan kehidupannya, aspek lain yang berperan untuk membantu keberlangsungan hidup manusia disebut juga dengan kebutuhan. Kebutuhan pokok manusia terdiri atas sandang (busana), papan (tempat tinggal), dan pangan (makanan), ketiga kebutuhan pokok manusia tersebut dibutuhkan untuk keseimbangan kehidupan manusia yaitu untuk mencapai suatu kesejahteraan.

(Apriliani et al., 2016)

Perkembangan zaman di dunia mode yang melaju pesat membuat keberadaan dan fungsi busana menjadi berubah. Fungsi busana saat ini bukan semata-mata untuk melindungi dari gangguan iklim, tetapi juga digunakan memenuhi syarat peradaban, sehingga tidak menyinggung rasa kesusilaan. Memenuhi syarat kesehatan, melindungi tubuh dari gangguan luar seperti panas, 
dingin dan gigitan serangga. Memenuhi rasa keindahan, menjadikan penampilan seseorang lebih menarik, sesuai dengan lingkungan dan kesempatan sehingga tidak menyimpang dari tempat ia berada, serta dibuat sedemikian rupa supaya kekurangan tubuh seseorang tersamarkan. (Rizali, 2000).(Eucheuma, 2004)

Busana merupakan salah satu hal pokok dalam kehidupan yang selalu mengikuti perkembangan zaman yang ada. Mode busana wanita paling banyak mendominasi dunia fashion dari keanekaragaman busana yang ada Semakin berkembangnya suatu ilmu pengetahuan dan teknologi maka manusia semakin terampil dalam menciptakan suatu busana atau pakaian, bahkan busana tidak hanya berfungsi sebagai penutup atau pelindung tubuh tapi busana kini di buat memberi nilai keindahan bagi pemakainya dengan model yang bermacam macam dan berubah, serta dapat berfungsi untuk menutup kekurangan seseorang yang memakainya.(Akhir, 2009).

Busana yang baik dan menarik tidak lepas dari faktor yang mempengaruhinya antara lain : bentuk tubuh, pemilihan mode, pemilihan bahan, usia pemakai, kesempatan (Wasia Roesbani dan Roesmini Soeryaatmaja, 1991:3). Nordholt (2005) mendefinisikan busana sebagai berikut: "Busana adalah cermin dari identitas, status hierarki, gender, memiliki nilai simbolik, dan merupakan ekspresi cara hidup tertentu. Pakaian juga mencerminkan sejarah, hubungan kekuasaan, serta perbedaan dalam pandangan sosial, politik dan religius."(Andhini, 2017). Para wanita sekarang ini sangat memperhatikan penampilannya. Mereka ingin selalu terlihat cantik dan menikuti trend fashion. Melihat fakta ini, maka tidak mengherankan apabila segmen remaja merupakan pasar yang paling potensial dalam produk fashion. Pada usia remaja, pilihan terhadap aktifitas, teman dan pakaian sangat penting untuk diakui oleh orang lain. Remaja lebih peduli pada trend yang sedang berkembang di pasar dibandingkan kelompok usia lain. Mereka tidak berperan menjadi trendsetter bagi orang-orang yang sebaya, melainkan juga mampumenjadi trendsetter bagi lingkungan sekitarnya (Tjahjono et al., 2013).

Pengepresan merupakan proses yang penting dalam pembuatan busana. Sebaik apapun teknik menjahit yang dilakukan, apabila teknik mengepres tidak tepat, tentunya tampilan akhir busana tidak akan rapi dan tidak sesuai bentuk yang diinginkan. Pengepresan merupakan proses melekatkan kain keras/pelapis pada bagian-bagian yang perlu diberi pelapis, seperti kerah, lipatan tengah muka, dan manset dengan menggunakan mesin press. Tujuan pengepresan agar bagianbagian yang perlu diberi pelapis tersebut hasilnya lebih rapi, rata atau tidak kembung. Proses pengepresan dengan mesin press (biasanya untuk bagian-bagain busana yang agak besar, untuk melicinkan bagian atas saku menggunakan setrika biasa., demikian juga untuk mengepres lapisan atau lipatan biasanya cukup menggunakan setrika biasa. Pengepresan menggunakan mesin press cukup dilakukan lebih kurang 2 menit untuk setiap kali press. (PENELITIAN PENGEPRESAN BUSANA WANITA, n.d.) 
Setiap jenis bahan memiliki daya tahan yang berbeda-beda terhadap panas. pengepresan dengan temperatur tinggi atau melebihi daya tahan bahan terhadap panas, seperti jenis bahan wol, sutra, dan jenis bahan lain yang tidak tahan terhadap panas tinggi dapat merubah warna bahan menjadi kekuningan. Selain warna bahan berubah, temperatur tinggi juga dapat menyebabkan kekuatan bahan melemah atau rapuh. Hal ini disebabkan karena kelembaban bahan yang dapat melindungi bahan menjadi berkurang akibat temperatur tinggi. Beberapa desain busana dengan detail seperti lipit, garis lengkung, dan lain sebagainya yang tidak dapat dibentuk hanya dengan jahitan membutuhkan pengepresan agar bagian-bagian busana tersebut nampak lebih rapi dan licin. (Yudiyanti, 2013)

Pelatihan yang dilakukan di Kelurahan Klamalu ini seluruh peserta di bimbing mengenai pengetahuan pengepresan, dari alat-alat yang digunakan sampai pada tahap-tahap yang harus di perhatikan dalam proses pengepresan busana terebut. Pengepresan merupakan proses yang penting dalam pembuatan busana. Sebaik apapun teknik menjahit yang dilakukan, apabila teknik mengepres tidak tepat, tentunya tampilan akhir busana tidak akan rapi dan tidak sesuai bentuk yang diinginkan. Sehingga diharapkan dengan adanya pelatihan ini masyarakat dapat meningkatkan kualitas pengepresan busana wanita yang di produksi di Kelurahan tersebut.

\section{METODE}

\section{Tempat dan Peserta}

Kegiatan Pelatihan dilaksanakan bertempat di Kantor Kelurahan Klamalu. Adapun peserta pelatihan yaitu masyarakat Kelurahan Klamalu.

\section{Bahan dan Alat Pelatihan}

Adapun bahan dan alat yang digunakan dalam pelatihan pengepresan busana wanita yakni bahan/ kain yang akan digunakan, setrika, mesin pres, papan setrika, bantalan setrika.

\section{Tahapan Pelatihan}

Sebelum melakukan pengepresan peserta harus mengetahui bagian-bagian mana yang memerlukan proses pengepresan, peralatan yang harus dipakai, teknik pengepresan yang perlu di perhatikan dan langkah - langkah pengepresan.

Adapun langkah - langkah pengepresan sebagai berikut : 1) Menyiapkan tempat kerja sesuai dengan standar ergonomic. 2) Menyiapkan alat pres utama dan pendukung. 3) Membersihkan dan memeriksa alat press sesuai prosedur. 4) Menyerahkan penempatan pada mesin sesuai persyaratan produk dan prosedur kerja. 5) Pengaturan suhu alat pengepresan pada waktu pelaksanaan disesuaikan dengan persyaratan produk. 6) Spesifikasi kain dan prosedur kerj. 7) Alat mesin pres setelah digunakan semua tombol di offkan (dimatikan). 


\section{HASIL DAN PEMBAHASAN}

\section{Kampuh}

Kampuh merupakan sisa sambungan dari hasil menyatukan bagian-bagian busana, seperti menyambung bahu badan depan dengan bahu belakang, sisi kiri muka dengan sisi kanan belakang, dan lain sebagainya.

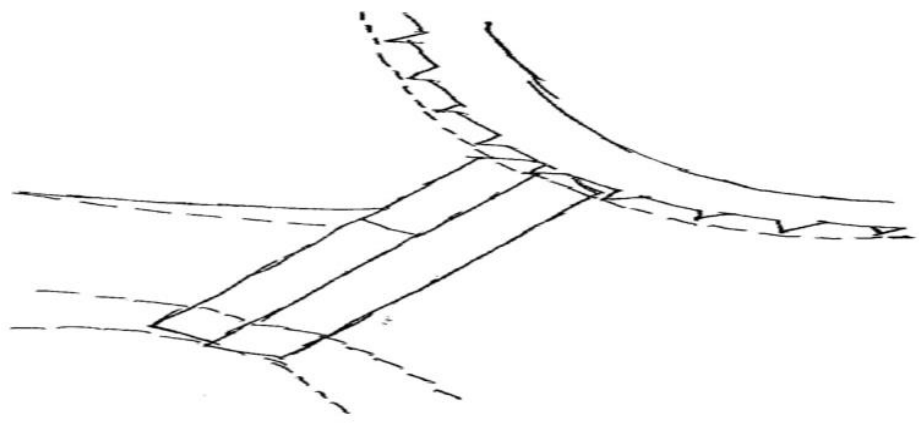

Gambar 1. Kampuh Buka

\section{Lipit}

Lipit atau lipatan pada pakaian berfungsi sebagai hiasan dan menambah kelonggaran, seperti lipit mati, lipit hadap, lipit sungkup, lipit plisse, lipit pipih, godet, dan lain sebagainya.

\section{Lapisan dalam (Interfancing)}

Pengepressan lapisan dalam bertujuan untuk melekatkan lapisan dalam pada bahan busana, yang bertujuan agar bahan busana menjadi lebih kuat, serta bentuk dan desain busana terpelihara. Bahan busana yang dilapisi lapisan dalam dapat pada keseluruhan bagian busana seperti pada jas, namun pada umumnya hanya dipergunakan pada bagian busana tertentu, seperti kerah, manset, bukaan bagian depan, ban pinggang, lapisan depun dan serip, serta bagian busana lainnya yang membutuhkan.
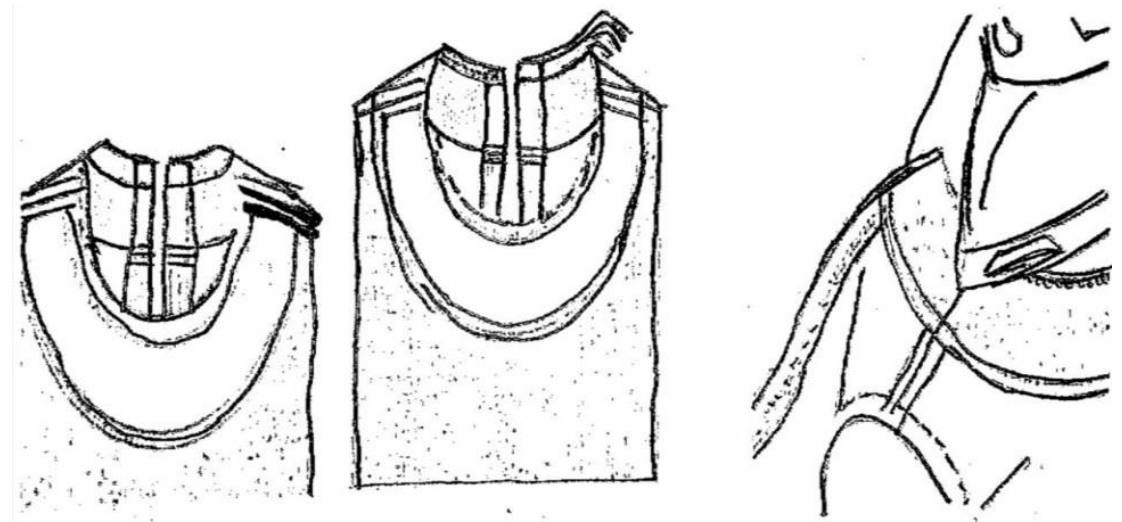

Gambar 2. Menyetrika Lapisan dalam 


\section{Komponen busana}

Komponen-komponen busana, seperti tutup kantong (klep), belahan busana, dan penyelesaian tepi, seperti kerah, leher, lengan, kelim.

\section{Peralatan Pengepresan}

Menurut Lewis (1960:381) dan Draper (1978:365) berbagai peralatan yang dapat menunjang keberhasilan pengepresan, antara lain sebagai berikut:

\section{Setrika}

Merupakan peralatan yang sangat membantu dalam membuat busana. Berbagai jenis setrika dilihat dari bentuknya, antara lain sebagai berikut.

\section{Setrika manual}

Seterika manual (non-automatic iron) adalah seterika yang tidak memiliki pengaturan temperatur, dengan sumber panas yang berasal dari tenaga listrik atau bara arang.

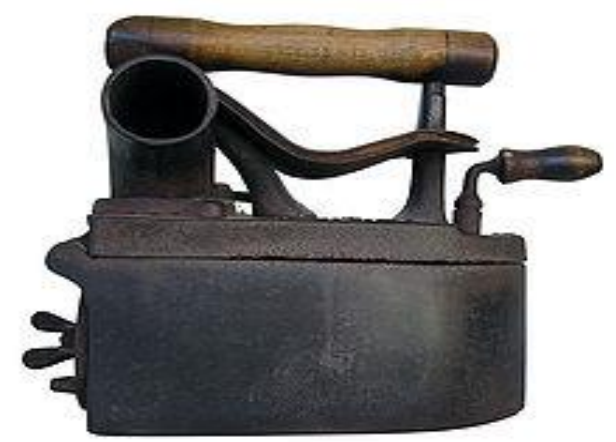

Gambar 3. Setrika manual

- Setrika listrik otomatis

Seterika listrik otomatis (automatic iron), yaitu jenis seterika yang menggunakan tenaga listrik dan memiliki pengontrol temperatur yang dapat disesuaikan dengan kebutuhan tiap jenis bahan tekstil.

- Setrika dengan semprotan air Soekarno (2005:9) menjelaskan, bahwa seterika dengan semprotan air merupakan jenis seterika yang mempunyai alat penyemprot air pada bagian depan 11 setrika yang airnya dapat disemprotkan pada bahan sambil menggerakan seterika agar bahan yang terkena air dapat lebih licin.

- Sterika uap 
Setrika uap merupakan setrika yang dapat mengubah air menjadi uap air yang dialirkan dari alas setrika langsung pada bahan, sehingga bahan terjaga kelembabannya selama proses pengepressan. Setrika uap yang digunakan industri busana saat ini menggunakan tenaga listrik atau tenaga gas.

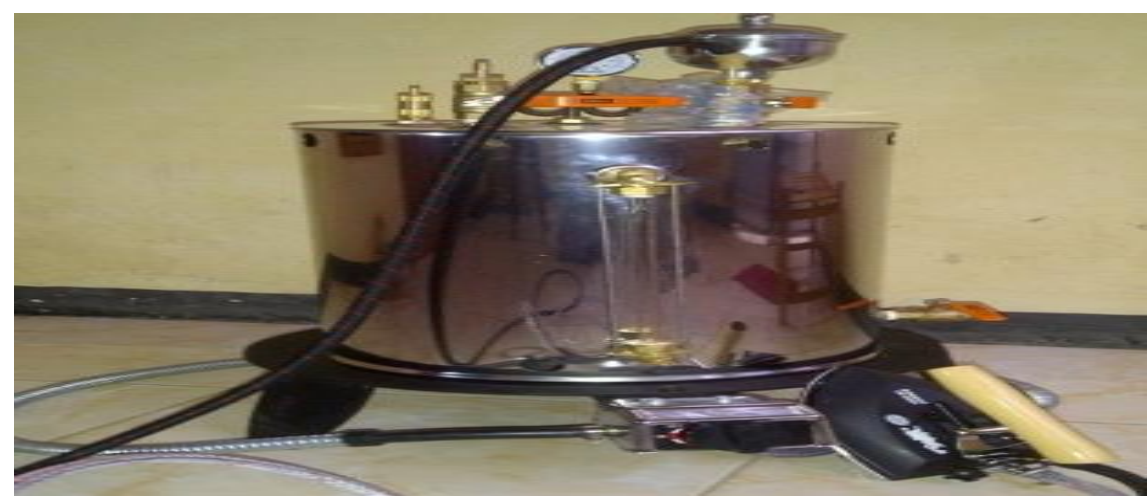

Gambar 4. Setrika Uap

\section{Mesin Pres}

Merupakan mesin khusus yang digunakan untuk mengepres lapisan dalam pada bahan busana. Kelebihan mesin pres dari setrika yaitu: alas mesin press lebih luas selain terdapat pengatur temperatur juga terdapat pengatur waktu terdapat penekan atau pemampat bahan.

Adapun beberapa bentuk mesin press dapat ditunjukkan pada gambar berikut ini.

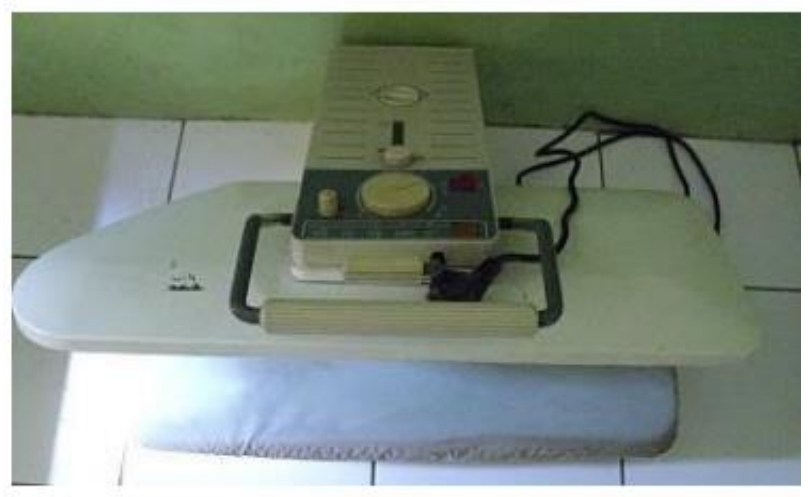

Gambar 5. Mesin pres kerah

\section{Papan Setrika atau meja setrika}

Digunakan sebagai alas untuk mengepres, Permukaan papan setrika sebaiknya luas, datar, dan rata agar dapat digunakan untuk busana yang berukuran lebar, ujung papan setrika berbentuk runcing agar memudahkan untuk menyarungkan bagian busana seperti gaun, blus, rok bawah, dan sebagainya (Poespo, 2005:97).

\section{Bantalan Setrika}


Merupakan peralatan yang dirancang dengan suatu bentuk permukaan yang seolah-olah merupakan kurva badan dan untuk memudahkan pengepressan bagian-bagian busana tanpa menyebabkan kerutan pada sisa bagian busananya (Poespo, 2005: 98). Berbagai jenis bantalan setrika, antara lain rol kampuh (seam roll), bantalan tailor (tailor's ham), papan meruncing (point presser), papan lengan baju (sleeve boards), dan balok penepuk (wooden clapper).

\section{Teknik Pengepresan yang perlu di perhatikan}

Hendrickson (2009:7) menjelaskan teknik yang perlu diperhatikan saat pengepresan, antara lain sebagai berikut:

\section{Kelembaban}

Lewis (1960:466) menyatakan bahwa, Kelembaban bahan bertujuan untuk melembutkan serat bahan yang akan dipres, sehingga bahan dapat lebih mudah untuk dibentuk. Bahan dapat dilembabkan dengan cara menyemprotkan air atau dengan menggunakan uap air dari setrika.

\section{Temperatur}

Setiap jenis bahan memiliki daya tahan yang berbeda-beda terhadap panas. Tabel berikut ini merupakan temperatur pengepresan pada setiap jenis bahan tekstil:

Tabel 1. Temperatur pengepresan pada bahan tekstil.

\begin{tabular}{cc}
\hline Jenis Serat & Temperatur Aman Untuk Pengepresan \\
\hline Katun & $218^{\circ} \mathrm{C}\left(425^{\circ} \mathrm{F}\right)$ \\
Linen & $232^{\circ} \mathrm{C}\left(450^{\circ} \mathrm{F}\right)$ \\
Sutra & $148^{\circ} \mathrm{C}\left(300^{\circ} \mathrm{F}\right)$ \\
Wol & $100^{\circ} \mathrm{C}\left(212^{\circ} \mathrm{F}\right)$ \\
Asetat & $135^{\circ} \mathrm{C}\left(275^{\circ} \mathrm{F}\right)$ \\
Triasetat & $204^{\circ} \mathrm{C}\left(400^{\circ} \mathrm{F}\right)$ \\
Akrilik & $135^{\circ} \mathrm{C}\left(275^{\circ} \mathrm{F}\right)$ \\
Modakrilik & $107^{\circ} \mathrm{C}\left(225^{\circ} \mathrm{F}\right)$ \\
Nilon & $135^{\circ} \mathrm{C}\left(275^{\circ} \mathrm{F}\right)$ \\
Poliester & $163^{\circ} \mathrm{C}\left(325^{\circ} \mathrm{F}\right)$ \\
Rayon & $135^{\circ} \mathrm{C}\left(275^{\circ} \mathrm{F}\right)$ \\
\hline
\end{tabular}

Sumber : Wyllie, 1987

\section{Tekanan}

Lewis (1960:466) menyatakan bahwa, Selain panas dan kelembaban yang dibutuhkan dalam pengepresan adalah sedikit tekanan mesin pres pada bahan. Tekanan setrika atau mesin pres terhadap bahan busana pada saat pengepresan bertujuan untuk memampatkan bahan menjadi bentuk yang diinginkan. Teknik penekanan bahan yang benar, yaitu dengan cara menekan atau memampat bahansilih berganti dan saling tumpang tindi.

\section{Waktu}


Waktu pengepresan atau lama berlangsungnya pengepresan sangat mendukung kelembaban, temperatur, dan tekanan dalam pengepresan. Pengepresan dengan kondisi bahan lembab, temperatur mesin pres sesuai dengan daya tahan bahan terhadap panas, dan ada tekanan dari mesin pres apabila waktu pengepresan cukup, maka dapat menghasilkan pengepresan yang maksimal. Draper (1978:362) menjelaskan bahwa proses pengepresan dilakukan dengan cara meletakan setrika pada bahan yangakan dipres kemudian sedikit menekan setrika selama beberapa waktu secara silih berganti dan saling tumpang tindih.

\section{Tahap- tahap pengepresan}

Tahapan kerja yang diperlukan dalam pengepresan, antara lain sebagai berikut: 1) Menyiapkan tempat kerja sesuai dengan standar. 2) Menyiapkan alat pres utama dan pendukung. 3) Membersihkan dan memeriksa alat press sesuai prosedur. 4) Menyerahkan penempatan pada mesin sesuai persyaratan produk dan prosedur kerja. 5) Pengaturan suhu alat pengepresan pada waktu pelaksanaan disesuaikan dengan persyaratan produk. 6) Spesifikasi kain dan prosedur kerja. 7) Alat mesin pres setelah digunakan semua tombol di offkan (dimatikan).

\section{SIMPULAN}

Kebutuhan pokok manusia terdiri atas sandang (busana), papan (tempat tinggal), dan pangan (makanan), ketiga kebutuhan pokok manusia tersebut dibutuhkan untuk keseimbangan kehidupan manusia yaitu untuk mencapai suatu kesejahteraan. Busana merupakan salah satu hal pokok dalam kehidupan yang selalu mengikuti perkembangan zaman. Semakin berkembangnya suatu ilmu pengetahuan dan teknologi maka manusia semakin terampil dalam menciptakan suatu busana. Mode busana wanita adalah paling banyak mendominasi dunia fashion dari keanekaragaman busana yang ada.

Pengepresan merupakan proses melekatkan kain keras/pelapis pada bagian-bagian yang perlu diberi pelapis, seperti kerah, lipatan tengah muka, dan manset dengan menggunakan mesin press. Tujuan pengepresan agar bagian- bagian yang perlu diberi pelapis tersebut hasilnya lebih rapi, rata atau tidak kembung. Setiap jenis bahan memiliki daya tahan yang berbeda-beda terhadap panas. pengepresan dengan temperatur tinggi atau melebihi daya tahan bahan terhadap panas, seperti jenis bahan wol, sutra, dan jenis bahan lain yang tidak tahan terhadap panas tinggi dapat merubah warna bahan menjadi kekuningan. Selain warna bahan berubah, temperatur tinggi juga dapat menyebabkan kekuatan bahan melemah atau rapuh. Hal ini disebabkan karena kelembaban bahan yang dapat melindungi bahan menjadi berkurang akibat temperatur tinggi. Beberapa desain busana dengan detail seperti lipit, garis lengkung, dan lain sebagainya yang tidak dapat dibentuk hanya dengan jahitan membutuhkan pengepresan agar bagian-bagian busana tersebut nampak lebih rapi dan licin.

\section{DAFTAR PUSTAKA}

Akhir, T. (2009). Dengan Aksentuasi Ruffles. 
Andhini, N. F. (2017). Journal of Chemical Information and Modeling, 53(9), 1689-1699.

Apriliani, D., Program, P., Pendidikan, S., \& Busana, T. (2016). Perbedaan hasil bustier ditinjau dari bahan pelapis (interfacing) dan teknik pengepresan lapisan dalam.

Eucheuma, A. K. (2004). No. 1-7. PENELITIAN PENGEPRESAN BUSANA WANITA. (n.d.).

Tjahjono, A., Semuel, P. H., Karina, R., Pemasaran, J. M., Petra, U. K., \& Siwalankerto, J. (2013).

Analisa Marketing Mix , Lingkungan Sosial, Psikologi Online Pakaian Wanita. Jurnal Manajemen Pemasaran Petra, 1(2), 1-9.

Yudiyanti, C. (2013). Pengaruh Temperatur Dan Waktu Pengepresan Lapisan Dalam ( Interfacing ) Terhadap Kualitas Bahan Jas. 